\title{
NFTs: Digital things and their criminal lives
}

Citation for published version (APA):

Mackenzie, S., \& Bērzina, D. (2022). NFTs: Digital things and their criminal lives. Crime Media Culture, 18(4), 527-542. [17416590211039797]. https://doi.org/10.1177/17416590211039797

Document status and date:

Published: 01/11/2022

DOI:

10.1177/17416590211039797

Document Version:

Publisher's PDF, also known as Version of record

Document license:

Taverne

\section{Please check the document version of this publication:}

- A submitted manuscript is the version of the article upon submission and before peer-review. There can be important differences between the submitted version and the official published version of record.

People interested in the research are advised to contact the author for the final version of the publication, or visit the DOI to the publisher's website.

- The final author version and the galley proof are versions of the publication after peer review.

- The final published version features the final layout of the paper including the volume, issue and page numbers.

Link to publication

\footnotetext{
General rights rights.

- You may freely distribute the URL identifying the publication in the public portal. please follow below link for the End User Agreement:

www.umlib.nl/taverne-license

Take down policy

If you believe that this document breaches copyright please contact us at:

repository@maastrichtuniversity.nl

providing details and we will investigate your claim.
}

Copyright and moral rights for the publications made accessible in the public portal are retained by the authors and/or other copyright owners and it is a condition of accessing publications that users recognise and abide by the legal requirements associated with these

- Users may download and print one copy of any publication from the public portal for the purpose of private study or research.

- You may not further distribute the material or use it for any profit-making activity or commercial gain

If the publication is distributed under the terms of Article $25 \mathrm{fa}$ of the Dutch Copyright Act, indicated by the "Taverne" license above, 


\section{NFTs: Digital things and their criminal lives}

\section{Simon Mackenzie iD}

Victoria University of Wellington, New Zealand
Crime Media Culture

(c) The Author(s) 2021

Article reuse guidelines: sagepub.com/journals-permissions DOI: $10.1177 / 17416590211039797$ journals.sagepub.com/home/cmc

(SAGE

\title{
Diāna Bērzina
}

Maastricht University, The Netherlands

\begin{abstract}
The extraordinary current craze around NFTs reflects their perceived value as a technological development that can bring greater certainty to questions of ownership and authenticity in fields like art and other collectibles. This is, among other things, the promise of crime prevention through technology, as ownership and authenticity are in the art world closely tied to criminal legal matters like theft, handling stolen goods and fraud. The crime prevention promise looks to fall flat though, as the technology seems to be less capable of delivering these benefits than has been assumed by its promoters. Much of the attraction of NFTs is therefore not actually based on effective crime prevention, but rather on hype. This paper explores the hype, and its relationship to the crime prevention promise of NFTs, through the lens of 'the social lives of things'. We argue that as well as social lives, things have criminal lives. Analysis sensitive to the criminal lives of things finds an NFT trading scene heated by emotion: excitement, attraction, temptation, speculative euphoria and acquisitive, possessive sentiment. This creates a sense of object agency more active than the cold traditional vision of material structure presented in standard criminological treatments of things-in-the-world as passive opportunity structures. The hyped NFT market trades in affecting objects that create crime in emotional as well as structural ways. We therefore arrive at a conclusion opposite to starting assumptions: far from preventing crime, NFTs are making it.
\end{abstract}

\section{Keywords}

Art crime, cryptocurrency, cybercrime, digital crime, fraud, NFT, non fungible token, online crime

\section{NFTs and the current craze}

NFTs are Non Fungible Tokens, a development in cryptocurrency on blockchains that has, at the time of writing, become an extraordinary craze. Blockchains are online ledgers recording transactions in a public way, hosting a trade in cryptocurrency tokens. Until recently almost all cryptocurrency

\section{Corresponding author:}

Diāna Bērzina, Department of Criminal Law and Criminology, Maastricht University, Faculty of Law, P.O. Box 616, MD, Maastricht 6200, The Netherlands.

Email: d.berzina@maastrichtuniversity.nl 
tokens were fungible, in other words one unit could be exchanged for any other of a similar value. There is no difference between one Bitcoin and another, just as there is no difference between one US dollar and another. NFTs, however, are non fungible, which means that each is distinct and original. This has led to a revolution in fields such as digital art, digital real estate, digital collectibles and even digital versions of seemingly mundane real-world commodities like sneakers and socks. We will focus the discussion here on art NFTs, acknowledging that these are only a subset of the overall universe of NFT-able things and that this universe is presently very fast moving. The range of things that NFTs apply to is expanding so rapidly that any attempt to provide coverage of all of the applications of the technology would be out of date well before this paper is published.

Even within the broad category of what we refer to here as 'art' NFTs there is much variety, for example when one considers art as encompassing values and intents like emotional expression, political activism, conceptual exercise, cultural production and economic strategy. We focus here on current trends in digital artworks which, as we will explain, are closely tied to the commodified, speculative, uber-capitalist cryptocurrency trading marketplace. This market includes both highend digital artworks comparable in many ways to the real-world fine art scene in terms of growing esteem and non-utilitarian conceptions of value (Plattner, 1998), and also more routine digital art that is designed to be collectible, such as avatars and art on digital collectors' cards. These latter are really a hybrid between artworld productions and other non-art related types of curios, rarities and collectibles. There is also digital NFT art that is designed with an inbuilt utilitarian value, for example the current trend in Axies. These are small cartoon bug NFTs embedded in a play-to-earn video game called Axie Infinity. Initial investment in purchasing Axies is repaid and multiplied over time by in-game rewards that can be cashed out in the real world. So while we use 'art' as a shorthand to refer to all the NFTs we discuss in this paper, it is important to bear in mind these distinctions that sit behind the reference and which reflect, as we might expect, the complexity of the much-discussed 'what is art' question more generally.

An NFT is a 'pointer' (Gerard, 2021). The art or other digital thing to which it refers is not normally part of the NFT. The NFT is a token stored on a blockchain that points to the art by containing a web address or some other reference that allows the art to be found on the internet. Often the art itself will be hosted on a gallery-type marketplace platform. So other than in exceptional cases of fairly simplistic digital pictures, the art is not 'on the blockchain', only the NFT is (Munster, 2021). When you buy the NFT, you get a token that purports to be both a definitive indicator of ownership of the digital art to which it is tied, and a definitive indicator of the authenticity of that artwork as the original, not a copy. In fact, as we will see, NFTs are not capable of definitively doing either of these things, at least in the terms that the concepts of ownership and originality are understood in the real-world art trade and the law.

Originality in digital art is a difficult concept: when exact copies can be made by right- clicking on screen, who is to say which is the original and whether there is any difference between that and the copies? As a matter of technological fact there may not be any differences. The original of a digital artwork might be a higher resolution than copies that are made but even that possible difference, perhaps not much discernible to the naked eye, may not be the case. NFTs solve the originality problem by providing proof of authorship and chain of ownership transmission on the blockchain so while there may not be a technical difference between an original digital artwork and its copies, there is a difference in terms of social meaning. By analogy, when Maurizio Cattelan duct-taped a banana to the wall of an art gallery and called it 'Comedian', it was originality and 
authorship that gave value to the work. Many people retorted 'anyone could have done that', but if they did it would be worthless; only the original has value. Comparably, the conventional artworld is full of fakes and it is sometimes hard to tell good ones from original works. An original Rothko is worth millions though, while a fake is worth next to nothing. A Rothko thought original but then discovered to be fake will see its value plummet to near zero (Wong, 2021b). Authorship and originality are the strongest drivers of value in art.

Ownership and originality/authenticity are also matters of core concern to analysts of art crime (Hufnagel and Chappell, 2019; Chappell and Polk, 2009). Fakes and fraud in the art market are in most cases crimes based on a misrepresentation of one or both of these issues: the suggestion that a work is by a famous author when it isn't (the originality/authenticity question in relation to fake art) or that the seller is the owner when they aren't (the ownership question in relation to stolen art). NFTs provide a crime prevention promise in both of these respects. The blockchain token that is the NFT is broadly considered by enthusiasts to be a secure online statement, recorded in the blockchain ledger, that the owner of the token is the owner of the art to which it refers, and that the art is the original work of the creator of the token ('Besancia', 2021). NFTs are only the latest technological advance to enter the anti-fraud art securitisation space: as technology develops it is regularly applied to crime prevention (Kerr, 2015). As one example from the art world, as long as 20 years ago Australian artist Pro Hart was embedding DNA in his paintings as proof of authenticity for buyers (The Age, 2002).

We will look at the NFT crime prevention argument here, and review the growing amount of evidence that suggests it is flawed. Instead of a market supported by an emergent crime prevention technology, the trade in NFTs is a market in hype, driven by emotional speculative and acquisitive impulses. We argue that far from preventing crime, NFTs are instrumental in making it. We make this suggestion with reference to some of the key themes of cultural criminology, especially the role of emotions in crime (Ferrell et al., 2004, 2008; Hayward, 2017). Within cultural criminology we look in particular to the 'agentic object' arguments encapsulated in the emerging literature on affect in criminology (e.g. Fraser and Matthews, 2019; Young, 2021a) which, as is the case with cultural criminology generally, corresponds and converses with similar themes in wider literature.

\section{How it started, how it's going}

In 2005, Matt Furie created a meme called Pepe the Frog, a sad-looking cartoon frog that subsequently featured on collectible Rare Pepe digital trading cards (Schachter, 2021). This was arguably the first precursor to the current NFT digital collectible hype. Various other NFT digital collectibles followed Pepe, mostly unremarkable and not achieving any significant impact on the crypto space until in 2017 a company called Larva Labs created Cryptopunks. Cryptopunks were the first unique cryptographic tokens on the blockchain, each punk being different and therefore collectible. Axiom Zen followed with Cryptokitties, also in 2017, moving the theme from punks to cats, but following a similar format: digital cartoonish blocky pixelated video-game style pictures attached to a token that allowed them to be traded on the Ethereum network, a major blockchain platform (Serada et al., 2021). Unlike the punks, the kitties could be bred, generating more NFT cats for the holder. In 2018 a cryptokitty sold for $\$ 140,000$ (Mala, 2018) foreshadowing the boom in NFT prices that we are now experiencing. 
Dapper Labs, an offshoot of Axiom Zen, then developed NBA Top Shots in collaboration with the US National Basketball Association. Top Shots are a series of short video clips, referred to as 'moments', which exist as NFTs on a blockchain called Flow that Dapper has developed. These videos, each 10-seconds or thereabouts, are highlights from basketball games, and they are collected and traded like collectible sports cards. They don't degrade like cards can, although with all of these new developments technological obsolescence sits as a concern in the background as platforms and blockchains upgrade, migrate or possibly die (Quirion, 2021). The NFT technology brings verifiable ownership and authenticity to each moment, and Top Shot has been described by collectors as 'the perfect trading card market' (McQuade, 2021), where scarcity is known, card condition has been rendered irrelevant and a list of all transactions the card has undergone is always available. The oddity for the layperson in all of this is that anyone can watch these videos, either on the Top Shot website or for many of them on You Tube: 'you don't need to own one to watch one. But if you own one, you are the only one to own it' (McQuade, 2021). Actually, it is not even the case that each moment is distinct, to the layperson. Dapper has created several editions of each moment, made marginally different by the use of serial numbers and labels such as 'cosmic' editions, mirroring the importance of serial numbers in the collectibles market for old baseball cards. What has been created has been described as a stock market for baseball (now basketball) cards: a simplified version of the sort of investing that share trading involves, combined with something that 'can turn from a hobby into an obsession. The mental impulse at play is elemental' (McQuade, 2021). The NBA Top Shot website explains: 'when you own \#23/49 of a legendary LeBron James dunk, you're the only person in the world who does' (Howcroft and Carvalho, 2021).

Prices in Top Shot and other NFTs have gone wild. On 22 February 2021 a collector paid $\$ 208,000$ for a LeBron James slam dunk on NBA Top Shot. Also in February 2021, a digital NFT of the Nyan Cat meme from 2011 - a retro video-game style gif of a flying cartoon cat - sold in an online auction for $\$ 560,000$ (Kinsella, 2021). In January 2021 an NFT investor collective called FlamingoDAO bought one of nine alien CryptoPunks, a batch of early and rare ones, for $\$ 762,000$. The punk was described as 'rudimentary pixel art' in one commentary (Seward, 2021). One of the representatives of FlamingoDAO who organised the purchase said 'I showed my mom and she was like, "What???"' (Seward, 2021). It might prove to be a good investment: in March another rare punk from the smoking zombie series, CryptoPunk 7804, sold for $\$ 7.6$ million.

In December 2020, the digital artist Beeple, who has spent the last 13 years making one digital artwork per day and for the most part posting them free on the internet, auctioned 21 NFTs of original works and multiple NFT editions of three others, on the online platform Nifty Gateway (Thaddeus-Johns, 2021). The total of that sale was $\$ 3.5$ million which seemed huge at the time but was put in perspective when through Christie's auction house he sold a composite NFT artwork, 'Everydays - the first 5000 days' - a collage of 5000 individual works - for $\$ 69$ million in March 2021, the third highest auction price ever achieved for a work by a living artist after Jeff Koons and David Hockney (Reyburn, 2021). In March 2021, Twitter founder Jack Dorsey auctioned his first ever tweet as an NFT - which simply reads 'just setting up my twttr' - with the winning bid coming in at $\$ 2.9$ million (Sandler, 2021).

The list of epic and seemingly deranged prices goes on. In late March 2021 someone bought an NFT of a 3D digital file of a house for $\$ 500,000$ (Sullivan, 2021). In a sale that was not the highest but perhaps the most absurd feature in this craze, a New York man NFT'd recordings of 
his farts and sold the most expensive one for about $\$ 430$ (Mak, 2021). This is a sale that is weird in so many ways but particularly, the seller notes, in terms of the difference between the NFT and the thing itself. The buyer, he reflects, has not bought a fart, nor even really a recording of a fart, since those recordings are still available for anyone to listen to on the internet. Rather, in taking ownership of the NFT the buyer has paid money for 'the idea of a fart' (Frishberg, 2021) which, we perhaps have to admit, is quite an artistic way of putting it; though whether recording your farts qualifies as conceptual or performance art is quite the open-ended question.

There are many purported benefits to tokenising art. Proof of authenticity and proof of ownership are the two most obvious, but the possibilities of NFT art are still developing. Art can now easily be fractionalised: so just as you can own 0.001 of a Bitcoin as easily (technically speaking, if not financially) as owning a whole one, so too can you own 0.001 of a digital artwork that may be far too expensive for you to afford more than a fraction of. Metakovan, the crypto 'whale' who bought Beeple's Everydays collage, did so for a bundle of NFTs he has fractionalised and sold ownership rights to through the crypto token B20. He owns $57 \%$ of the circulating supply of that token, while the rest has been sold on the cryptocurrency market (Castor, 2021). Anyone can therefore buy a B20 token on the crypto market which gives them a share in a basket of NFT artworks including the Beeple collage along with other high end digital artworks: a financial investment vehicle that is modelled on the more conventional idea of a unit trust.

For the author of an artwork, a key benefit is the automation of resale royalties. The rights an NFT awards a purchaser are not altogether clear, especially since the NFT's relationship with realworld legal considerations like copyright remain vague. What is clear though is that the author can write into the NFT any terms they want, so for example Beeple's NFTs give the artist a $10 \%$ royalty on every resale in perpetuity (Thaddeus-Johns, 2021). In the traditional world of conventional art sales some countries have similar so-called Artists' Resale Rights (Salisbury, 2019), but many do not and in these latter cases after the author sells the work they have no continuing financial interest; all further proceeds of subsequent sales go to the sellers and their agents. An NFT resale royalty, automatically deducted through the smart contract mechanism governing NFT sales, looks likely to be highly lucrative given what seems like more of a tendency in buyers of digital art to 'flip' their purchases than is the norm in the conventional art market. Many of the works bought from Beeple's December Nifty Gateway 'drop' were flipped for substantial profits within minutes of having been bought, and his NFT 'Crossroad', a 10 second video art piece featuring a naked Donald Trump, having been bought for \$67,000 in October 2020 was resold in early 2021 on Nifty Gateway for \$6.6 million (Howcroft and Carvalho, 2021).

As the Crossroad example shows, not only have these prices risen dramatically, they have done so sometimes in a very short space of time. A Beeple NFT purchased by a client in December 2020 for just under $\$ 1000$ was worth $\$ 300,000$ by March 2021 (Quarmby, 2021). An investor who bought a LeBron James Cosmic NFT on NBA Top Shot for $\$ 40,000$ in January 2021 sold it for $\$ 125,000$ in February (Howcroft and Carvalho, 2021).

\section{The social and criminal lives of things}

Commodities are argued to be 'thoroughly socialised thing[s]' (Appadurai, 1986: 6). Appadurai (1986: 13) proposes to view commodities as things in a particular situation, a situation which can be applicable to anything at various stages of its social life. Kopytoff (1986: 73) argues that 
commoditisation should be viewed as 'a process of becoming' rather than a particular state of being. Therefore, commodities like persons have social lives (Appadurai, 1986; Kopytoff, 1986). At the commodification stage the most relevant feature of the thing is its exchangeability (Appadurai, 1986). By looking at commodities this way, one can avoid the fruitless task of trying to separate commodities from other types of things and instead look at the potential of any thing to become a commodity at a specific time. For instance, due to technological advances it is now possible to commodify and exchange something that was not previously commodifiable - digital land for example (see Young, 2021b) or Beeple's art which as we noted has been transformed, through the use of NFTs, from non-commodity to commodity, previously posted free on the internet and now sold for millions. Beeple is said to have discovered NFTs around October 2020, and 6 months later he is a multi-millionaire.

Commodification may therefore be technologically facilitated, but it is a social process. Only a small part of the value of a Rolex watch is in its function as a device to tell the time. The rest is in other aspects of its collectability, and in its capacity to do the job of social signalling (Zeiler, 2018). Conspicuous consumption is one aspect of collecting, marking social status through the medium of economic wealth in ways that are only loosely connected to questions of utility, if at all. Cryptocurrency traders want 'Lambos' (Mackenzie, 2021) not because Lamborghinis are particularly great or useful cars, though they may be, but mainly because they are status symbols entirely unnecessary purchases that denote such significant wealth that throwing money around on such things is considered financially inconsequential, though socially very consequential (Pathak, 2018). On this view, it is humans who endow things with attributes and motivations, and these processes of social construction are context-dependent and may provide for variety over time in the social lives of objects.

A 'follow the things' approach is the methodological prescription that follows this position, as only by focusing on the social lives and trajectories of material objects can we understand 'the human transactions and calculations that enliven things' (Appadurai, 1986: 5). Similarly, Marshall (2008: 60), coming from archaeological perspective, proposes to view objects 'as social interventions and possible events'. A sudden appearance of 'a distinctive new object' could signal a type of sudden social change (Marshall, 2008: 6). For instance, as the distinction between online and offline is breaking down, a recognition of this socio-technical fusion brings more appreciation of what the point of NFTs are, and what their value might be. The co-founder of OpenSea, one of the largest online markets for NFTs, says: 'If you spend 10 hours a day on the computer, or 8 hours a day in the digital realm, then art in the digital world makes tonnes of sense - because it is the world' (Howcroft and Carvalho, 2021).

So things have meanings, and they go through changes in their social lives. However, things created by one group of people can embody experiences and emotions that a different group might not be able to comprehend. An example might be trench-art objects created by soldiers (Saunders, 2005). In other words, it is reasonable to argue that for many types of analysis the physical aspects of any object are less important than its interpretation. Which aspect of the object's life one creates connection with may vary from person to person. The object physically does not change, but for every person its meaning is different and therefore on the level of social understanding and perhaps also associated practical use, it may appear to be a different object to each. Sometimes, as with art, we can be invited to share another person or group's interpretation. Thus we are educated into an appreciation of the value and 
perhaps desirability of artwork; our own initial views reworked to align with professed cultural norms (Bourdieu, 1984).

As commodification can be seen as just a phase in the object's life, one can write a biography of a commodity, or indeed any other thing, in the same way as one would write a biography about a person (Kopytoff, 1986). A person cannot be fully understood based on just one point in their history and comparably objects change through their lives, and have 'the capability of accumulating histories, so that the present significance of an object derives from the persons and events to which it is connected' (Gosden and Marshall, 1999: 170). However, it is a 'reciprocal construction of value' (Appadurai, 1986: 20) as people's standing can be improved by possessing certain objects, or even simply being involved in a culture of appreciating them (Bourdieu, 1984). For this reason, among others, the social lives of humans and objects are intertwined and 'objects make people just as much as people make objects' (Saunders, 2005: 78-79). This kind of reciprocal view of the social lives of objects lends the things in question an active role in the recursive production of social structure. On this view, while object meaning is inscribed upon physical form by people, this is not only a one-sided interpretive human practice but is an act of engaging with and trying to understand objects, in which the objects themselves may have some independent voice. In art, this 'voice' seems to be best summarised as 'affect': the emotional component of appreciating art or, in other words, how it makes you feel.

If objects can be understood as having social lives - moving through space and time with associated changes in use and inscribed meaning as they travel and interact with different people and groups - then they can in some cases have criminal lives too. Like people, objects can be thought of as sometimes drifting into crime (cf. Matza, 1964), or being caught up in criminal situations. Certain objects may provide clearer examples of such criminal lives than others: the gun used in a hold-up; the spray-paint can put to work in graffiti; the coca leaf refined into cocaine and trafficked to a receptive market. Criminology, with some exceptions, has of course followed sociology in being more naturally concerned with the actions, dispositions, choices and intentions of people and social structures than with object agency and physical structures. In that respect, criminology is open to the broad Latourian critique of being 'too social', and diminishing a full consideration of the role of objects in actor-networks where people and things co-exist (Latour, 2005). Just as the 'social lives of objects' is a perspective emerging out of a reaction against a sociology that has been too exclusively human, so too the criminal lives of objects may be a revealing perspective for a criminology that aspires to similar 'reassembling' ends.

\section{The social and criminal lives of NFTs}

NFTs in digital art and other digital collectibles seem to be experiencing the same recursive constructivist social forces that other wealth and status objects do: their high prices are because of what they mean, and what they mean is tied to those high prices: 'since everyone is connected with everyone online, why would you only want to signal wealth, status and fame exclusively in your offline life?' (Zeiler, 2018). We described the current state of play with NFTs as a craze in the introduction to this paper, and in a craze people go crazy. They bid crazy prices for online tokens based often on little understanding of the precise nature or legality of what they are buying. At the time of writing we seem to be in what analysts call the euphoria phase of the market cycle, sometimes also colloquially referred to as a bubble (Shaw, 2021b), the next phase being a crash 
or at least a sizeable correction. In the euphoria of NFT creation and collection, the various aspects of the allure of the objects have engaged people in an unreflective pseudo-land-grab compared, inevitably, to tulip-mania (Shaw, 2021b; Wong, 2021a) and taking on the appearance in some collecting corners of the digital art world of a sort of collective frenzied delirium.

It seems clear that there is an emotional dynamic in NFT trading, in which the objects are al/luring. The digital art or other collectible may be 'alluring' to collectors in ways similar to the allure of physical art (Kersel, 2015). And beyond that kind of aesthetic allure, further 'lure' comes from the financial prospects of the things as investment vehicles, and as symbolic forms of cultural capital (Bourdieu, 1984). So in matters of enjoyment, profit and distinction, NFTs engage with their audience in ways that seem to approach irresistibility for some people. On the spectrum of agency these may appear to be more active, rather than passive, ways-of-being for objects: 'affects' rather than 'effects' (Fraser and Matthews, 2019). Affecting objects influence human behaviour (Young, 2021a), achieving perhaps subtle forms of social change that render as problematic the traditional view of objects as just physical - or in our case technological/digital - 'stuff' that sits around waiting to be given meaning by the social world. To the contrary, these objects are part of the forces creating the social world (Philippopoulos-Mihalopoulos, 2015), and with NFTs it is perhaps not difficult to see people being drawn into the objects' orbit, existentially influenced and manipulated by these new 'things' as phenomena (cf. Hayward, 2015).

The 'affects' of NFTs can be seen in, among other indicators of significant lure, a willingness to buy NFTs on terms that give buyers a rather limited use. Some NFT licences retain the creative and intellectual works in the creator, allowing buyers only restricted use such as to display the art online. They might choose to do this in a virtual world like Decentraland which now hosts galleries and museums where collections of NFTs can be viewed (Wong, 2021b). In these limited-use cases, 'buyers are really just purchasing bragging rights' (Kastrenakes, 2021b).

Dapper Labs has produced a template NFT licence that goes further: while the creator retains 'all legal right, title and interest to the Art, and all intellectual property rights therein' (other than insofar as these may be passed on to the buyer in terms of the individual licence created), the buyer is given the right to use, copy and display the art for private use and to monetise it in commercial use up to a ceiling of $\$ 100,000$ per year (Dapper Labs, 2018). Beeple's NFT sales included, as we mentioned, a perpetual royalty of $10 \%$ to be paid to him on each subsequent transfer of ownership. So: anything goes, but buyers may find that they have not bought as much 'ownership' as they thought. Jack Dorsey sold his tweet as an NFT but others have too, which raises the question: if you are not the CEO of twitter like Dorsey, is a tweet you have written really yours to sell in the first place or does it belong to the company ('Besancia', 2021) - and if it is not yours to sell, what is the buyer of your NFT'd tweet getting? NBA Top Shot 'moments', for another example, have a long list of conditions including that NBA, not the buyer, owns the copyright. Aside from selling it through the NBA website, the buyer cannot modify or commercialise it without NBA's prior written consent. This may conflict with common expectations on ownership rights (Roberts, 2021), though Dapper correctly notes in advertising its model licence that some of the rights it awards, like commercialisation, extend significantly beyond what would normally be permitted where one purchases intellectual property such as protected designs.

NFTs exist as online claims to rights that may or may not be recognised by real-world legal systems. As indicated, the creator might pass copyright in the work on to the buyer by including such a term in a contract that is part of the NFT on the blockchain. Whether this would be 
recognised in all jurisdictions is uncertain. Copyright may also be relevant where a digital artwork is 'minted' into an NFT without the author's consent: the process of minting an NFT does not require the creator to prove ownership of copyright in the image being minted. There are several examples of this kind of rip-off having happened; usually the original artist spots their work being sold as an NFT after an entrepreneurial fraudster has copied it from the artist's Instagram page or similar (Dodds, 2021; Kelly, 2021; Munster, 2021; Stephen, 2021). Relying on this kind of private policing of the digital art market is not ideal though. Some scammers have pretended to be the famous artist they are ripping off, copying their art from one platform and creating a fake account in their name on another where they mint the copies as NFTs and sell them as originals, impersonating the creator (NFT Industry News, 2020).

There is even a web service called Tokenized Tweets, which allows any twitter user to monetise any other user's tweets simply by replying to the original tweet and tagging @tokenizedtweets, which turns them into an NFT owned by the tagger. In the case of digital artists those tweets often include copies of artworks, so when they are tokenised by 'rando's' as one artist, RJ Palmer, called the anonymous users doing this to his tweets, copyright issues are created (Munster, 2021). Another artist, Corbin Rainbolt, complained on twitter about people tokenising his art tweets only to find that this made matters worse: 'Once I started getting it out there, there were people who tagged the tweet in which I was complaining about NFTs, in order to make it into an NFT about the exact thing I was complaining about' (Munster, 2021).

Some NFTs purport to allocate exclusive rights to artwork that has long been in the public domain. An example is the 'DEAL WITH IT' meme, a picture of a laid back dog wearing sunglasses that has been used, as memes are, many thousands of times in internet chat forums (Kastrenakes, 2021a). The person claiming to be the originator of the meme has NFT'd and sold the sunglasses and the text for $\$ 27,000$, selling 'the full rights to this image \& meme and the Photoshop template used to create it' (Kuhn, 2021). As one commentator notes, however: 'this is a right anyone had before, judging by the number of DEAL WITH IT memes in circulation' (Kuhn, 2021). Whether he is correct in that assumption is, again, not entirely clear but it is certainly true that what was once effectively public property has now been privatised, and this in turn has raised speculative questions about what would happen if the owner of the NFT tried to regulate its use on the internet.

The claim to ownership in this DEAL WITH IT case comes from the assertion of the person who created the NFT to be the author of the original work, a situation that as we have noted may not always be the case. So although the CEO of the platform that sold the meme, Foundation, says that in the future NFTs will be the mechanism by which all art is 'attributed to its rightful owner' (Kuhn, 2021), the process of minting NFTs does not seem adequately to provide a gatekeeping control over who does that minting in the first place and whether they are, in fact, the 'rightful owner'.

As well as ownership, let us briefly discuss authenticity. Innuendo is an issue fairly well known to the art world: producing work 'in the style of' a famous artist. Copying an artist's technique but creating art that is not a direct copy of anything that already exists does not usually give rise to legal issues unless there is a misrepresentation that the art is actually the work of the more famous artist (Polk, 2016). To imply such would be fraud. Innuendo is a difficult issue, and even more so for digital art which is easily copied and altered. An artist using the pseudonym Pest Supply has sold $\$ 900,000$ worth of Banksy lookalike NFTs on OpenSea and 
Rarible, two of the biggest platforms for NFT art online (Shaw, 2021a). The style of the works seems clearly intended to suggest that Bansky produced them, and Pest Supply is a name that brings to mind Pest Control, Banksy's authentication company. Pest Supply has now been blocked from using OpenSea but not before netting nearly a million dollar in sales amid speculation that perhaps Bansky was behind it after all. It seems clear now though that he was not.

Overall, the most problematic feature of NFTs is that the token is not the artwork. The terms and conditions of Christie's sale of Beeple's Everydays in March 2021 specify that buyers must acknowledge that 'the ownership of an NFT carries no rights, express or implied, other than property rights for the lot (specifically, digital art tokenised by the NFT)' and 'you acknowledge and represent that there is substantial uncertainty as to the characterisation of NFTs and other digital assets under applicable law' (Christie's, 2021). Which is a round-about way of saying that you are buying a crypto token ('digital art tokenised') that may not be recognised in law as giving you the rights you thought you were buying in terms of ownership and use of the artwork. One commentator has likened this to the registration scam: 'like selling your name on a star, or a square foot of land on the moon' (Gerard, 2021). You may get a digital certificate of ownership and authenticity, but that might be all you are getting.

Further, because the token only points to the artwork rather than incorporating it, a variety of problems can manifest. Multiple NFTs could be created all referring to copies of the same piece of digital art and each fraudulently claiming to be proof of the original (Gerard, 2021). Or, for example, the art that the NFT refers to could be swapped out. A collector on OpenSea did this simply to demonstrate the flaws in the NFT concept, at least when it is hosted on a centralised platform. He advertised 26 artworks for sale on the platform and then changed them all to photos of carpets half way through the sale, saying 'All discussions about the value of NFTs are meaningless as long as the token is not inseparable from the artwork itself. What is the meaning of creating an unforgeable token on a highly secured network if somebody can alter, relink or destroy your possession?' (Cointelegraph, 2021).

So while the technology underwriting NFTs may in some aspects be transformative, the opportunities for criminal misrepresentation remain fairly predictable. The result of the NFT-onthe-blockchain but art-on-the-web context is that if an author whose artwork has been ripped off and tokenised tells a hosting website to take the art down, 'all the hapless NFT buyer is left with is a string of letters and numbers that someone, somewhere swears is worth as much as a luxury car due to its tenuous and likely illegal relationship to someone else's art' (Munster, 2021). Yet neither can it be said that a decentralised future for NFT art - i.e. not hosted by any particular web platform that some person or group owns - may look much better. While it is now very difficult to store art on the blockchain along with the token, it may be easier in the future as popular solutions like the IPFS network continue to develop. The IPFS is Inter Planetary File Storage - a decentralised network where files are stored across a vast number of computers around the world, removing control over them from any one centralised authority. In such a case though, it will likely be impossible to 'take the art down' since the blockchain cannot be altered, so illicit and copyright infringing art might continue to circulate even after it has been declared illegal ('Besancia', 2021).

Compared to some of these scams, the theft of NFTs seems fairly mundane. This happened in mid-March 2021 when Nifty Gateway, one of the major NFT-hosting online platforms, was hacked (Powers, 2021). Some users who had not set up two-factor authentication on their accounts were 
hacked, it is thought with key-logger malware on their computers. The NFTs they owned on Nifty Gateway were sold by the hackers to other customers in a matter of minutes netting hundreds of thousands of dollars, and their credit cards held on file were used to buy more NFTs which were similarly sold (Di Liscia, 2021). The hack was discovered quite quickly by some of the affected owners and because the art was still on the Nifty Gateway platform, having been sold to other platform users, it was recovered. Had the hackers transferred the art outside the Nifty Gateway ecosystem it would likely have been lost because of the irreversible nature of blockchain transactions (Powers, 2021).

These stories of the social and criminal lives of NFTs draw attention to aspects of their 'seductions' (Katz, 1988) that require them to be seen as more than simply passive vehicles for crime. Some branches of criminology would no doubt be happy with a strictly pragmatic approach to interpreting NFT crime, citing for example the opportunities (eg. Felson and Clarke, 1998) for abuse that the technology creates, or the problem of achieving active 'capable guardianship' (Felson, 1994) in an online domain constructed around the idea of a decentralised blockchain that is designed to be trustless (i.e. operating mechanically, unsusceptible to significant human interference or abuse). However, a more object-agentic approach to NFT crime would inquire into the technology as more than just a passive or inert opportunity framework that is an enabler of criminal fraud or intellectual property crimes. Rather than anodyne online artefacts that are the victims of abuse, a 'criminal lives' approach would see NFTs as a disruptive technological advance that sets in motion a series of criminal consequences.

Following the thread as we unravel it of this view of agentic, affecting objects, we can think about the social biographies of objects as sometimes including criminal episodes, such as where NFTs are involved in scams. The current acquisitive frenzy seems to be bound up with the 'affect' of the objects. In some cases, the frenzy is abused by entrepreneurial scammers and fraudsters who are lured by the criminal prospects the new digital field has generated. In this context, it may make sense to go beyond basic structure-choice approaches like opportunity theory and reach for analysis that considers the objects as actants rather than just acted-upons. A component of the social lives of objects may in some cases be their criminal lives, as nodes at the centre of networks of activity in which the criminals and the victims can be conceived of not only as people, but also as including the objects themselves.

\section{Conclusion}

The social lives of NFTs are an interesting study in technology and social networks. The technology itself generates social ties that go beyond what is usual in commercial or consumer exchange transactions in which the new owner incorporates the item into their regime and overwrites any traces of meaning associated with the seller (Jenkins et al., 2014). In the case of the NFT, the previous owner will always be part of the object's social history as the chain of ownership will be permanently recorded on the blockchain. Now that digital art can be fractionalised and it is possible to own just a percentage of the artwork, a single object's social life can be fragmented and it can exist in multiple, simultaneous networks, creating the social in a web of connections that are made by the object. Also, recall that depending on the creator's licence terms incorporated into the NFT, their authorial interest may subsist throughout. Beeple, referring to the $10 \%$ resale royalty clause in his NFTs, has mused on the socialising effects of 
these kinds of objective qualities: 'When you buy the artwork you are sort of entering into a relationship with me' (Thaddeus-Johns, 2021). The social lives of NFTs are intricately tied, through the creation and maintenance of such relationships, to the implication of crime prevention through proof of ownership and authenticity.

The promise of technology in solving problems of crime is often overstated. In suggesting an answer to questions of originality and ownership in the market for art and other collectibles, as well as a growing range of other real-world things like real estate, fashion clothing and videogame content, we have identified one major aspect of the core promise of NFTs as being crime prevention. Questions of value around whether a thing is original or not, or owned by the seller or not, may look like straightforward economic questions about how much something is worth. But in art as in other collectibles, aside from the kinds of often-manufactured scarcity we have discussed, the key deciding factor in value is actually a question of crime: if the thing is not the original but a fake being held out to be the original, it is fraud. If the seller does not own the thing they are offering for sale, it is likely a case of theft or handling stolen goods. Layered on top of these criminal law interpretations of events is the discourse of so-called 'IP crime' (Mackenzie, 2010), which in many cases is not actually crime (though it may be closely related) but a form of civil infringement involving a breach of the law in relation to copyright, trademarks or another type of 'offence'.

If we acknowledge that the value proposition of NFTs is actually - in some key respects if not entirely - a crime prevention proposition, then probing that crime prevention proposition is important. Away from the hyped techno-commercial discourse around the great leap forward this online development is said to represent, a closer look reveals a series of flaws in the crime prevention proposition made by NFTs which threaten to undermine current claims to their transformative value. The combination of new technology, stories of absurd profits and the disruptive status and consumerist implications of lives increasingly led online, together with the heady enthusiasm for taking part in a contemporary craze, has proved to be a potent cocktail in which the social lives of NFTs have unfolded. Meanwhile their less obvious criminal lives have also generated for some NFTs biographies that include theft, fraud and other legal wrongs, tainting both those individual 'objects' and the overall impression of a new emergent security assemblage as it has been valorised in the ideology of the trustless, decentralised, immutable blockchain.

We started this exploration of the social and criminal lives of NFTs with the premise that NFTs might represent a technological breakthrough promoting crime prevention. A more accurate view would be that the promise of crime prevention here is still developing. A less corruptible link between the token, the artist and the original artwork would be required to fulfil that promise. Currently that immutable and uncorruptible link does not exist and it is not technologically feasible to develop in the near term. In these circumstances it is helpful to take a more nuanced view of the current NFT craze than one which accepts them wholesale as the solution to crime prevention in art dealing and other markets. That more nuanced view should include recognition that NFTs have affecting properties: exerting emotional pulls on collectors and speculators, generating acquisitive excitement, fomenting temptation experienced as aesthetic and financial lure, and encouraging status accumulation and display in the digital realm. In thinking about these affects, structuring and in turn being reinforced by a market in hype, NFTs can be thought of as making crime more so than preventing it. 


\section{Funding}

The author(s) disclosed receipt of the following financial support for the research, authorship, and/or publication of this article: The funding for this research was provided by the European Research Council (ERC) under the European Union's Horizon 2020 research and innovation programme (grant agreement no 804851).

\section{ORCID iD}

Simon Mackenzie (iD) https://orcid.org/0000-0002-9294-4732

\section{References}

Appadurai A (ed.) (1986) The Social Life of Things: Commodities in Cultural Perspective. Cambridge: Cambridge University Press.

'Besancia' (2021) The Art of Copy(right) on the Blockchain. NonFungible. Available at: https://nonfungible. com/blog/the-art-of-copyright-on-the-blockchain (accessed 26 March 2021).

Bourdieu P (1984) Distinction: A Social Critique of the Judgement of Taste. Cambridge, MA: Harvard University Press.

Castor A (2021) Metakovan, the mystery Beeple art buyer, and his NFT/DeFi scheme. Available at: https://amycastor.com/2021/03/14/metakovan-the-mystery-beeple-art-buyer-and-his-nft-defi-scheme/ (accessed 25 March 2021).

Chappell D and Polk K (2009) Fakers and forgers, deception and dishonesty: An exploration of the Murky world of art fraud. Current Issues in Criminal Justice 20(3): 393-412.

Christie's (2021) Ecommerce conditions of sale - New York. Available at: https://www.christies.com/pdf/ onlineonly/ECOMMERCE\%20CONDITIONS\%200F\%20SALE\%20-\%20NY-24Feb2021.pdf (accessed 9 April 2021).

Cointelegraph (2021) NFT special! Beeple's millions, Banksy profits, problems for Kings of Leon. Magazine by Cointelegraph. Available at: https://cointelegraph.com/magazine/2021/03/13/beeple-millions-banksyprofits-kingsofleon-problems-030713 (accessed 26 March 2021).

Dapper Labs (2018) NFT License V2. Available at: https://www.nftlicense.org (accessed 26 March 2021).

Di Liscia V (2021) Reports of stolen art on NFT marketplace raise issues for crypto collectors. Hyperallergic. Available at: https://hyperallergic.com/629328/reports-of-stolen-art-on-nft-marketplace-raise-issues-forcrypto-collectors/ (accessed 26 March 2021).

Dodds L (2021) The crypto-art market is being infiltrated by fakes, thieves, and scammers. The Telegraph. Available at: https://www.telegraph.co.uk/technology/2021/03/15/crypto-art-market-infiltrated-fakesthieves-scammers/ (accessed 26 March 2021).

Felson M (1994) Crime and Everyday Life. Thousand Oaks, CA: Pine Forge Press.

Felson M and Clarke RV (1998) Opportunity makes the thief: Practical theory for crime prevention. Policing and Reducing Crime Unit, Police Research Series Paper 98. London: Home Office.

Ferrell J, Hayward K, Morrison W, et al. (eds) (2004) Cultural Criminology Unleashed. London: RoutledgeCavendish.

Ferrell J, Hayward K and Young J (2008) Cultural Criminology: An Invitation. London: Sage.

Fraser A and Matthews D (2019) Towards a criminology of atmospheres: Law, affect and the codes of the street. Criminology \& Criminal Justice. Epub ahead of print 11 September 2019. DOI: $10.1177 / 1748895819874853$.

Frishberg H (2021) NYC man sells fart for $\$ 85$, cashing in on NFT craze. New York Post. Available at: https:// nypost.com/2021/03/18/nyc-man-sells-fart-for-85-cashing-in-on-nft-craze/ (accessed 26 March 2021).

Gerard D (2021) NFTs: crypto grifters try to scam artists, again. attack of the 50 Foot Blockchain. Available at: https://davidgerard.co.uk/blockchain/2021/03/11/nfts-crypto-grifters-try-to-scam-artists-again/ (accessed 25 March 2021).

Gosden C and Marshall Y (1999) The cultural biography of objects. World Archaeology 31(2): 169-178. 
Hayward K (ed.) (2017) Cultural Criminology. London: Routledge.

Hayward K (2015) Cultural criminology: Script rewrites. Theoretical Criminology 20(3): 297-321.

Howcroft E and Carvalho R (2021) How a 10-second video clip sold for $\$ 6.6$ million. Reuters. Available at: https://www.reuters.com/article/us-retail-trading-nfts-insight-idUSKCN2AT1HG (accessed 25 March 2021).

Hufnagel S and Chappell D (2019) The Palgrave Handbook on Art Crime. London: Palgrave Macmillan.

Jenkins R, Molesworth M and Scullion R (2014) The messy social lives of objects: Inter-personal borrowing and the ambiguity of possession and ownership. Journal of Consumer Behaviour 13(2): 131-139.

Kastrenakes J (2021a) The 'deal with it' glasses are being sold as an NFT. The Verge. Available at: https:// www.theverge.com/2021/3/4/22313211/deal-with-it-meme-nft-auction-ryder-ripps (accessed 26 March 2021).

Kastrenakes J (2021b) Nyan Cat is being sold as a one-of-a-kind piece of crypto art. The Verge. Available at: https://www.theverge.com/2021/2/18/22287956/nyan-cat-crypto-art-foundation-nft-sale-chris-torres (accessed 26 March 2021).

Katz J (1988) Seductions of Crime: Moral and Sensual Attractions in Doing Evil. New York, NY: Basic Books.

Kelly L (2021) Crypto art fraud on rarible sparks governance discussion. Crypto Briefing. Available at: https:// cryptobriefing.com/crypto-art-fraud-rarible-sparks-governance-discussion/ (accessed 24 March 2021).

Kerr J (2015) The Securitization and Policing of Art Theft: The Case of London. Farnham: Ashgate.

Kersel MM (2015) The lure of the artefact? The effects of acquiring eastern Mediterranean material culture. In: Knapp AB and Van Dommelen P (eds) The Cambridge Prehistory of the Bronze and Iron Age Mediterranean. Cambridge: Cambridge University Press, pp.367-378.

Kinsella E (2021) Is this the next art-market bubble? A unique NFT for the popular 'nyan cat' GIF just sold for a whopping $\$ 560,000$. Artnet. Available at: https://news.artnet.com/market/nyan-cat-nft-sellsfor-560000-1945679 (accessed 25 March 2021).

Kopytoff I (1986) The cultural biography of things: Commoditization as process. In: Appadurai A (ed.) The Social Life of Things: Commodities in Cultural Perspective. Cambridge: Cambridge University Press, pp.64-91.

Kuhn D (2021) The problem of authenticity in NFT art. Coindesk. Available at: https://www.coindesk.com/ authenticity-nft-art-column (accessed 24 March 2021).

Latour B (2005) Reassembling the Social: An Introduction to Actor-Network Theory. Oxford: Oxford University Press.

Mackenzie S (2010) Counterfeiting as corporate externality: Intellectual property crime and global insecurity. Crime, Law and Social Change 54(1): 21-38.

Mackenzie S (2021) There are no Lambos on the moon! Cryptocurrency scams and criminology. Victoria University of Wellington Public Lecture Series. Available at: https://www.wgtn.ac.nz/about/our-story/newsevents/public-lecture-series (accessed 20 August 2021).

Marshall Y (2008) The social lives of lived and inscribed objects: A Lapita perspective. The Journal of the Polynesian Society 117(1): 59-101.

McQuade D (2021) A short, lucrative, and depressing journey into NBA top shot. Defector. Available at: https://defector.com/nba-top-shot-story/ (accessed 24 March 2021).

Mak A (2021) How much money people have made-or lost—selling farts, blog posts, and cat tweets as NFTs. Slate. Available at: https://slate.com/technology/2021/03/nfts-fees-rarible-opensea-auction-profit. html (accessed 26 March 2021).

Mala E (2018) Who spends $\$ 140,000$ on a CryptoKitty? New York Times, 18 May.

Matza D (1964) Delinquency and Drift. New York, NY: John Wiley.

Munster B (2021) People are stealing art and turning it into NFTs. Vice. Available at: https://www.vice.com/en/ article/n7vxe7/people-are-stealing-art-and-turning-it-into-nfts (accessed 26 March 2021).

NFT Industry News (2020) 7 ways scammers are stealing your NFTs + NFT weaknesses exposed? NFT Plazas. Available at: https://nftplazas.com/7-nft-scams/ (accessed 26 March 2021).

Pathak S (2018) When Lambo? How Lamborghini became the status brand of the crypto boom. Available at: https://digiday.com/marketing/lambo-lamborghini-became-status-brand-crypto-boom/ (accessed 19 March 2021). 
Philippopoulos-Mihalopoulos A (2015) Spatial Justice: Body, Lawscape, Atmosphere. Abingdon: Routledge.

Plattner S (1998) A most ingenious paradox: The market for contemporary fine art. American Anthropologist 100(2): 482-493.

Polk K (2016) Fakes and forgeries in art, and the more specific term "art fraud": A criminological perspective. Oxford Research Encyclopedias. Available at: https://oxfordre.com/view/10.1093/acrefore/9780190264079.001.0001/acrefore-9780190264079-e-280 (accessed 9 April 2021).

Powers B (2021) Lessons from the Nifty Gateway NFT Heist: Not your keys, not your art. Coindesk. Available at: https://www.coindesk.com/nifty-gateway-nft-hack-lessons (accessed 26 March 2021).

Quarmby B (2021) Investor 'stumbles' into 30,000\% gain after buying Beeple NFT for $\$ 969$. Coin Telegraph. Available at: https://cointelegraph.com/news/investor-stumbles-into-30-000-gain-after-buying-beeplenft-for-969 (accessed 25 March 2021).

Quirion A (2021) What is an NFT and why should archivists pay attention. Archeota 7(1): 10-12.

Reyburn S (2021) JPG file sells for $\$ 69$ million, as NFT mania gathers pace. New York Times, 16 March 2021.

Roberts JJ (2021) So you bought an NBA top shot NFT. What do you actually own? Decrypt. Available at: https://decrypt.co/60808/so-you-bought-an-nba-top-shot-nft-what-do-you-actually-own (accessed 26 March 2021).

Salisbury LW (2019) It's not that easy: Artist resale royalty rights and The ART Act. Center for Art Law. Available at: https://itsartlaw.org/2019/07/01/its-not-that-easy-artist-resale-royalty-rights-and-the-art-act/ (accessed 13 July 2021).

Sandler R (2021) Jack Dorsey's first tweet fetched $\$ 2.9$ million in NFT sale-And he donated proceeds to charity. Forbes. Available at: https://www.forbes.com/sites/rachelsandler/2021/03/22/jack-dorseys-firsttweet-fetched-29-million-in-nft-sale-and-he-donated-proceeds-to-charity/?sh=3fd2399d3e2f (accessed 24 March 2021).

Saunders NJ (2005) Culture, conflict and materiality: The social lives of Great War objects. In: Finn B and Hacker B (eds) Materializing the Military. London: Science Museum, pp. 77-94.

Schachter K (2021) Kenny Schachter gets sucked into the surreal NFT vortex... and makes a fortune overnight in the new virtual art market. Artnet. Available at: https://news.artnet.com/opinion/kennyschachter-tk-1946256 (accessed 25 March 2021).

Serada A, Sihvonen T and Harviainen JT (2021) CryptoKitties and the new ludic economy: How blockchain introduces value, ownership, and scarcity in digital gaming. Games and Culture 16(4): 457-480.

Seward Z (2021) Early CryptoPunk digital collectible sells for \$762k in ether. Coindesk. Available at: https:// www.coindesk.com/early-cryptopunk-digital-collectible-sells-for-762k-in-ether (accessed 24 March 2021).

Shaw A (2021a) Banksy-style NFTs have sold for $\$ 900,000$ - but are they the real deal and does it even matter? The Art Newspaper, 22 February.

Shaw A (2021b) Sorry to burst your bubble: NFT prices slump 70\%. The Art Newspaper, 8 April.

Stephen B (2021) NFT mania is here, and so are the scammers. The Verge. Available at: https://www.theverge.com/2021/3/20/22334527/nft-scams-artists-opensea-rarible-marble-cards-fraud-art (accessed 25 March 2021).

Sullivan H (2021) Digital home sells for $\$ 500,000$ in latest NFT sale. The Guardian. Available at: https://www. theguardian.com/artanddesign/2021/mar/23/digital-home-sells-for-500000-in-latest-nft-sale (accessed 24 March 2021).

Thaddeus-Johns J (2021) Beeple brings crypto to Christie's. New York Times, 24 February.

The Age (2002) Cheeky Pro Hart puts DNA signature on his paintings, The Age. Available at: https://www. theage.com.au/entertainment/art-and-design/cheeky-pro-hart-puts-dna-signature-on-his-paintings20020307-gdu0z1.html (accessed 23 July 2021).

Wong E (2021a) Are NFTs the next tulips? Medium. Available at: https://medium.com/quantdart/are-nfts-thenext-tulips-2430ac50d102 (accessed 9 April 2021).

Wong JI (2021b) NFTs explained: Coveted by Chamath, Vaynerchuk, Cuban, and regular people, too; but what the heck are they? B2, The Business of Business. Available at: https://www.businessofbusiness.com/articles/nft-non-fungible-token-crypto-art-beeple-christies-auction-explainer/ (accessed 26 March 2021). 
Young A (2021a) Architecture as affective law enforcement: Theorising the Japanese Koban. Crime, Media, Culture. Epub ahead of print 17 February 2021. DOI: 10.1177/1741659021993527.

Young M (2021b) Virtual land can be worth more than the real thing after plot sells for record $\$ 1.5 \mathrm{M}$. Cointelegraph. Available at: https://cointelegraph.com/news/virtual-land-can-be-worth-more-than-the-realthing-after-plot-sells-for-record-1-5m (accessed 16 April 2021).

Zeiler M (2018) Crypto collectibles/non fungible tokens (NFTs) : The Killer App for the blockchain. Medium. Available at: https://medium.com/token-valley/crypto-collectibles-non-fungible-tokens-nfts-the-killerapp-for-the-blockchain-96fe229b7b57 (accessed 24 March 2021).

\section{Author biographies}

Simon Mackenzie is Professor of Criminology and Head of the School of Social and Cultural Studies at Te Herenga Waka - Victoria University of Wellington and a Researcher in the Department of Criminal Law and Criminology at Maastricht University. He researches white collar crime and organised crime.

Diāna Bērziṇa is a Researcher on the project 'Trafficking Transformations: Objects as Agents in Transnational Criminal Networks' based in the Department of Criminal Law and Criminology at Maastricht University. Her research is focused on art and heritage crime. 